\title{
The primary cilium functions as a mechanical and calcium signaling nexus
}

\author{
Kristen L Lee', Marie D Guevarra', An M Nguyen ${ }^{1,2}$, Mardonn C Chua ${ }^{1,3}$, Yingxiao Wang ${ }^{4}$ \\ and Christopher R Jacobs ${ }^{1 *}$
}

\begin{abstract}
Background: The primary cilium is an antenna-like, nonmotile structure that extends from the surface of most mammalian cell types and is critical for chemosensing and mechanosensing in a variety of tissues including cartilage, bone, and kidney. Flow-induced intracellular calcium ion $\left(\mathrm{Ca}^{2+}\right)$ increases in kidney epithelia depend on primary cilia and primary cilium-localized $\mathrm{Ca}^{2+}$-permeable channels polycystin-2 (PC2) and transient receptor potential vanilloid 4 (TRPV4). While primary cilia have been implicated in osteocyte mechanotransduction, the molecular mechanism that mediates this process is not fully understood. We directed a fluorescence resonance energy transfer (FRET)-based $\mathrm{Ca}^{2+}$ biosensor to the cilium by fusing the biosensor sequence to the sequence of the primary cilium-specific protein Arl13b. Using this tool, we investigated the role of several $\mathrm{Ca}^{2+}$-permeable channels that may mediate flow-induced $\mathrm{Ca}^{2+}$ entry: PC2, TRPV4, and PIEZO1.

Results: Here, we report the first measurements of $\mathrm{Ca}^{2+}$ signaling within osteocyte primary cilia using a FRET-based biosensor fused to ARL13B. We show that fluid flow induces $\mathrm{Ca}^{2+}$ increases in osteocyte primary cilia which depend on both intracellular $\mathrm{Ca}^{2+}$ release and extracellular $\mathrm{Ca}^{2+}$ entry. Using siRNA-mediated knockdowns, we demonstrate that TRPV4, but not PC2 or PIEZO1, mediates flow-induced ciliary $\mathrm{Ca}^{2+}$ increases and loading-induced Cox-2 mRNA increases, an osteogenic response.

Conclusions: In this study, we show that the primary cilium forms a $\mathrm{Ca}^{2+}$ microdomain dependent on $\mathrm{Ca}^{2+}$ entry through TRPV4. These results demonstrate that the mechanism of mechanotransduction mediated by primary cilia varies in different tissue contexts. Additionally, we anticipate that this work is a starting point for more studies investigating the role of TRPV4 in mechanotransduction.
\end{abstract}

Keywords: Mechanotransduction, Primary cilium, Calcium signaling, Osteocyte, Kidney epithelia, Biosensor

\section{Background}

Mechanotransduction is a process by which cells sense and convert mechanical signals into biochemical and transcriptional changes. The calcium ion $\left(\mathrm{Ca}^{2+}\right)$ is a ubiquitous second messenger that regulates numerous signaling pathways. Despite how universal $\mathrm{Ca}^{2+}$ is, discrete intracellular signaling mechanisms occur because $\mathrm{Ca}^{2+}$ gradients are spatiotemporal and do not comprise one general pool that changes uniformly. For example, there are discrete microdomain $\mathrm{Ca}^{2+}$ signals including " $\mathrm{Ca}^{2+}$ sparks," "Ca ${ }^{2+}$ sparklets," and "scraps" that modulate

\footnotetext{
*Correspondence: christopher.jacobs@columbia.edu

'Department of Biomedical Engineering, Columbia University, 351 Engineering Terrace, MC 8904, 1210 Amsterdam Ave, New York, NY 10027, USA

Full list of author information is available at the end of the article
}

constriction and relaxation in vascular smooth muscle cells $[1,2]$. Mechanical loading generates rapid and temporal intracellular $\mathrm{Ca}^{2+}$ increases in many cell types including osteocytes, osteoblasts, neurons, and kidney cells. $\mathrm{Ca}^{2+}$ mobilization is required for flow-induced prostaglandin E2 $\left(\mathrm{PGE}_{2}\right)$ release and flow-induced osteopontin gene regulation in osteocytes, demonstrating that $\mathrm{Ca}^{2+}$ is upstream of mechanotransduction activities and paracrine signaling $[3,4]$.

The primary cilium is an antenna-like, nonmotile structure that extends from the surface of most mammalian cell types into the extracellular space [5,6]. While initially considered a vestigial structure, in the past decade, several labs have demonstrated that primary cilia are critical for chemosensing and mechanosensing in a variety of tissues including cartilage, bone, and kidney 
[7-13]. The osteocyte primary cilium deflects with mechanical stimulation and mediates mechanotransduction at the transcriptional level; however, previous experiments have not resolved $\mathrm{Ca}^{2+}$ within the primary cilium from the cytosol [14].

Recent advances in monitoring ciliary $\mathrm{Ca}^{2+}$ mobilization have improved our understanding of the primary ciliummediated mechanism of mechanotransduction in kidney epithelia. In the past, traditional diffusive BAPTA-based fluorescent indicator dyes were used to measure intracellular $\mathrm{Ca}^{2+}$ levels but did not target specific subcellular domains. In some pivotal studies, Praetorious and Spring and Nauli et al. demonstrated that primary cilia are required for mechanically induced $\mathrm{Ca}^{2+}$ increases in kidney epithelial cells $[12,13,15]$. The dependence of flow-induced $\mathrm{Ca}^{2+}$ increases on kidney epithelia primary cilia and the presence of mechanosensitive $\mathrm{Ca}^{2+}$-permeable channels on the ciliary membrane suggest that mechanical loading opens stretch-activated ion channels on the primary cilium that mediate $\mathrm{Ca}^{2+}$ entry. In the last couple of years, Delling et al., Su et al., and Jin et al. directed genetically encoded single fluorescence $\mathrm{Ca}^{2+}$ biosensors to the primary cilium using a variety of ciliary targeting sequences in human retina pigmented epithelia and kidney epithelial cells [16-18]. Su et al. and Jin et al. exposed kidney epithelial cells to fluid flow, which bent primary cilia and increased ciliary and cytosolic $\mathrm{Ca}^{2+}$ levels $[17,18]$. The $\mathrm{Ca}^{2}$ ${ }^{+}$-permeable channel polycystin-2 (PC2) associates with the mechanosensitive protein polycystin-1 and localizes to the primary cilium. Jin et al. reported that flow-induced $\mathrm{Ca}^{2+}$ elevations occur first in the primary cilium and are followed by cytosolic $\mathrm{Ca}^{2+}$ mobilization. Both ciliary and cytosolic $\mathrm{Ca}^{2+}$ increases were dependent on PC2 [18]. Furthermore, blocking ryanodine receptors inhibited cytosolic $\mathrm{Ca}^{2+}$ increases without affecting the flow-induced ciliary $\mathrm{Ca}^{2+}$ response $[18,19]$. Collectively, these recent flow studies on kidney epithelia primary cilia demonstrate that fluid flow activates PC2 through which extracellular $\mathrm{Ca}^{2+}$ enters and triggers ryanodine receptors in $\mathrm{Ca}^{2+}$-induced $\mathrm{Ca}^{2+}$ release.

Current knowledge of the osteocyte primary ciliummediated mechanism of mechanotransduction is relatively poor compared with recent progress in kidney epithelia primary cilium mechanotransduction research. Our group previously used the fluorescent dye Fura 2-AM to demonstrate that flow-induced $\mathrm{Ca}^{2+}$ increases in MLOY4 osteocyte-like cells are independent of primary cilia and stretch-activated channels, which is different from kidney cells [14]. While these results suggest that the osteocyte primary cilium-regulated mechanism of mechanotransduction is not linked to intracellular $\mathrm{Ca}^{2+}$ levels, it is unknown if the local primary cilium $\mathrm{Ca}^{2+}$ environment is distinct from the cytosol. We hypothesized that the osteocyte primary cilium mediates mechanotransduction by forming a distinct
$\mathrm{Ca}^{2+}$ microdomain. Therefore, the objective of this study was to monitor flow-induced ciliary $\mathrm{Ca}^{2+}$ levels and elucidate the intricate role of the osteocyte primary cilium as a biochemical and mechanical signaling nexus.

In this study, we directed a fluorescence resonance energy transfer (FRET)-based $\mathrm{Ca}^{2+}$ biosensor to the primary cilium by fusing a biosensor sequence to the sequence of the primary cilium-specific protein Arl13b. The modified YC3.6 $\mathrm{Ca}^{2+}$-sensitive FRET-based biosensor with the ECFP-YPet donor-acceptor pair contains a calmodulin $(\mathrm{CaM})$ region with four $\mathrm{Ca}^{2+}$-binding domains [20]. Binding of $\mathrm{Ca}^{2+}$ results in a conformational change that increases FRET signal, which is characterized by decreased ECFP and increased YPet fluorescence [21]. YPet as an acceptor produces the largest FRET dynamic range in live mammalian cells compared to Citrine, Venus, or cpVenus [20]. Using a targeted version of a FRET-based $\mathrm{Ca}^{2+}$ biosensor containing ECFP and YPet and the diffusive $\mathrm{Ca}^{2+}$ indicator dye Fura Red, we detected ciliary and cytosolic $\mathrm{Ca}^{2+}$ increases within individual MLO-Y4 cells exposed to fluid flow stimulation. Additionally, we examined the role of several $\mathrm{Ca}^{2+}$-permeable channels on the primary cilium: $\mathrm{PC} 2$, transient receptor potential vanilloid 4 (TRPV4), and PIEZO1. Coste et al. recently characterized mechanically activated current in neuroblastoma cells and proposed that the multipass transmembrane ion channels PIEZO1 and PIEZO2 mediate mechanically activated cation activity, leading us to explore the role of PIEZO channels in 223osteocyte mechanotransduction [22]. Our data demonstrate that TRPV4, but not PC2 or PIEZO1, mediates flow-induced ciliary $\mathrm{Ca}^{2+}$ increases and a loading-induced osteogenic response at the transcriptional level. Collectively, our study demonstrates that the osteocyte primary cilium microdomain is distinct from the cytosol and that sources of loading-induced ciliary $\mathrm{Ca}^{2+}$ mobilization are different in kidney epithelia and osteocytes. These are the first measurements of $\mathrm{Ca}^{2+}$ signaling within the osteocyte primary cilium, and we anticipate this work is a starting point for more studies investigating the role of TRPV4 in osteocyte mechanotransduction [23].

\section{Methods}

\section{Plasmid construction}

Drs. Yingxiao Peter Wang and Mingxing Ouyang previously developed a calcium-sensitive FRET-based biosensor composed of an ECFP donor, calmodulin region, M13 calmodulin-binding region, and YPet acceptor (CaB). Drs. Kenji Kontani and Kristen Verhey generously shared with us the Arl13b gene. We fused Arl13b to the $\mathrm{N}$ terminus of $\mathrm{CaB}$ using a 15 -amino-acid-long flexible linker to form Arl13b-L-CaB (ALC)[24]. Deletions of $\mathrm{Trp}^{3}$ and $\mathrm{Phe}^{17}$ in the M13 region were performed to block changes in FRET during $\mathrm{Ca}^{2+}$ increases, serving as 
negative controls of $\mathrm{CaB}$ and $\mathrm{ALC}$ (mutCaB and mutALC) [25].

\section{Cell culture and transfection}

MLO-Y4 osteocyte-like cells (a gift from Dr. Lynda Bonewald of the University of Missouri-Kansas City) were cultured in MEM alpha (Life Technologies) with $5 \% \mathrm{FBS}, 5 \% \mathrm{CS}$, and $1 \% \mathrm{PS}$ at $37^{\circ} \mathrm{C}$ in $5 \% \mathrm{CO}_{2}$. Using the BTX 360 with a $300-\mathrm{V}, 100-\Omega, 1,000-\mu \mathrm{F}$ pulse, 1.25 million cells were transfected with $10 \mu \mathrm{g}$ plasmid by electroporation. Cells were co-transfected with the ALC plasmid and $0.5 \mathrm{nmol}$ siRNA. siRNA sequences included Pkd2 (5' -CCUCUUGGCAGUUUCAGCCUGUAAA-3'), Trpv4 (5'-GAUGGACUGCUCUCCUUCUU GUUGA-3'), and Piezo1 (5'-CACCGGCAUCUACGUCAAAUA-3') [22]. Transfected MLO-Y4 cells were seeded onto collagen I-coated glass slides (\#1.5 glass, Warner Instruments) at a density of 4,000 cells $/ \mathrm{cm}^{2}$ and cultured for 3 days in reduced serum containing 2.5\% FBS and 2.5\% CS. IMCD cells (purchased from ATCC ${ }^{\ominus}$, CRL-2123 $3^{\mathrm{mm}}$ ) were cultured in DMEM (Life Technologies) with 10\% FBS and 1\% PS. Transfected IMCD cells were seeded onto fibronectincoated glass slides at a density of $8,000 \mathrm{cells} / \mathrm{cm}^{2}$ and cultured for 3 days in 1\% FBS. Prior to imaging, cells were incubated in $20 \mu \mathrm{M}$ Fura Red-AM (Life Technologies, F-3021) with $0.1 \%$ Pluronic $^{\circ}$ F-127 (20\% solution in DMSO) (Life Technologies) for $1 \mathrm{~h}$ at room temperature to label cytosolic $\mathrm{Ca}^{2+}$.

\section{Imaging flow chamber}

Slides were placed in the RC-30 Confocal Imaging Chamber (Warner Instruments) and attached to a syringe containing phenol red-free alpha MEM with $1 \%$ FBS and 1\% CS for MLO-Y4 cells or phenol red-free DMEM with 1\% FBS and 1\% PS for IMCD cells. MLOY4 cells were stimulated with oscillatory fluid flow resulting in a 10-dyn $/ \mathrm{cm}^{2}$ shear stress, and IMCD cells were stimulated with steady fluid flow resulting in a 1$\mathrm{dyn} / \mathrm{cm}^{2}$ shear stress, both within physiologic range for each cell type. Thapsigargin was added to the imaging media at a final concentration of $10 \mu \mathrm{M}$ for appropriate samples for a 20-min rest period and maintained at the same concentration during flow. A separate syringe with $10 \mu \mathrm{M}$ ionomycin was connected to the chamber to verify cell viability after the initial flow stimulus.

\section{$\mathrm{Ca}^{2+}$ imaging in cilia and cytosol}

One fluorescing cell per slide was selected at random for imaging. The selected cilium was focused on, with the cell body captured within the field of view on an Olympus IX71 inverted epifluorescence microscope with a 1.30 N.A. $\times 40$ oil immersion objective. Donor excitation was achieved on a xenon lamp using a 430/24-nm filter while images were collected simultaneously using a
Quad-View system (QV2, Photometrics) with emission filters of 470/28, 530/30, and 641/75 nm. Cells were left to rest for $20 \mathrm{~min}$ prior to imaging. For calibration studies, we added ionomycin at a final concentration of $5 \mu \mathrm{M}$ and $\mathrm{CaCl}_{2}$ at a final concentration of $0.1,0.25$, and $0.5 \mathrm{mM}$. Baseline signal was recorded for $30 \mathrm{~s}$ followed by $5 \mathrm{~min}$ of flow. Images were taken at $4 \mathrm{~Hz}$ with a 150 ms exposure.

\section{Image analysis}

Images of each sample were trimmed to regions of interest that tightly enclosed the primary cilium or cell during imaging. Using MATLAB, images were corrected for background and bleedthrough and a pixel-by-pixel basis, resulting in signal only in the cilium and cytosol. Specifically, using MetaMorph, the same background region for ECFP and YPet images was selected from the untrimmed image far from the sample within the field of view, and bleedthrough coefficients were calculated prior to performing experiments [26]. To aid in peak detection, the average intensity data of a region of interest over time was smoothened using a 1D Savitsky-Golay filter with a window width of 31, and a fourth-degree smoothing polynomial. Oscillation amplitude was identified by finding local maxima with MATLAB. A baseline value for each sample was determined by averaging the baseline signal collected $30 \mathrm{~s}$ prior to flow. The maximum baseline oscillation amplitude was defined as maximum oscillation amplitude that occurred during the recording of the baseline signal, $30 \mathrm{~s}$ prior to flow. The $\mathrm{Ca}^{2+}$ peak height was defined as the peak amplitude that occurred during flow exposure. Multiple $\mathrm{Ca}^{2+}$ peaks may occur during the 5-min period of flow. A sample was considered responsive if a $\mathrm{Ca}^{2+}$ peak height was equal to or greater than 1.5 times the maximum baseline oscillation amplitude $[27,28]$. Not all samples were analyzed due to movement of the sample out of plane.

\section{Antibodies}

We used the following primary antibodies: rabbit antipolycystin-2 (Santa Cruz, sc-25749), rabbit anti-sera to TRPV4 (generously provided by Heller group), rabbit antiPIEZO1 (Novus NBP1-78537 for immunostaining and NBP2-10504 for Western blot), mouse anti-acetylated alpha tubulin (Abcam, ab24610), and mouse anti-actin (Abcam, ab11003). We used the following secondary antibodies: Alexa Fluor 488 goat anti-rabbit IgG (Life Technologies, A11008), Alexa Fluor 568 goat anti-mouse IgG (Life Technologies, A11031), goat anti-rabbit IgG-HRP (Santa Cruz, sc-2004), and HRP goat anti-mouse Ig (BD Biosciences, 554002).

\section{Immunocytochemistry and confocal microscopy}

MLO-Y4 and IMCD cells were seeded on 35-mm glassbottom dishes at approximately 1,000 and 2,000 cells/ 
$\mathrm{cm}^{2}$, respectively. Upon reaching $80 \%-90 \%$ confluence after 2 days of culture, cells were fixed with $10 \%$ formalin, permeabilized with $0.1 \%$ Triton X-100, and blocked with $10 \%$ goat serum and $1 \%$ BSA in PBS. Cells were labeled with primary antibodies for PC2, TRPV4, PIEZO1, and acetylated alpha tubulin followed by incubation in appropriate Alexa Fluor-labeled secondary antibodies. Nucleic stain was achieved using DAPI $(0.5 \mathrm{mg} / \mathrm{mL}$; 1:100). Confocal z-stack images were obtained on a Leica SP5 using a 1.46 N.A. $\times 100$ oil immersion objective. Maximum X-Z projections were constructed with Leica software.

\section{Western blot}

Cells transfected with Pkd2-, Trpv4-, Piezo1-, and MedGCscrambled siRNA (Life Technologies) were lysed in RIPA buffer (Santa Cruz, sc-24948) supplemented with sodium orthovanadate, PMSF, and protease inhibitor cocktail 3 days post electroporation. Five micrograms of each protein sample was run through NuPAGE Novex $^{\circ} 4 \%-12 \%$ Bis-Tris gels (Life Technologies). After electrophoresis, proteins were transferred to Invitrolon ${ }^{\mathrm{Tw}}$ PVDF membranes (Life Technologies). The membranes were cut in half to separately label actin bands. Membranes for PC2, PIEZO1, and actin were blocked with 5\% BSA (Sigma-Aldrich), and membranes for TRPV4 were blocked with 5\% nonfat milk. HRP-conjugated antibodies were detected with chemiluminescence (Clarity Western ECL Substrate, Bio-Rad) on a Fujifilm LAS-4000 biomolecular imager.

\section{Flow chamber}

Transfected MLO-Y4 cells were seeded onto collagen Icoated glass slides at approximately $5,000 \mathrm{cells} / \mathrm{cm}^{2}$ and cultured for 3 days. Slides were placed in larger, custommade parallel-plate flow chambers $(56 \times 24 \times 0.28 \mathrm{~mm})$ so that sufficient amounts of RNA are isolated for gene expression analysis. Chambers with slides were incubated for $30 \mathrm{~min}$ and then exposed to $5 \mathrm{~min}$ of oscillatory fluid flow (OFF) at $1 \mathrm{~Hz}$ with a peak shear stress of $10 \mathrm{dyn} / \mathrm{cm}^{2}$. Slides were removed from chambers after $55 \mathrm{~min}$, and RNA was isolated immediately.

\section{Quantitative real-time RT-PCR}

RNA was extracted from cells using TriReagent (Sigma-Aldrich) and isolated, followed by cDNA synthesis using TaqMan reverse transcriptase (Applied Biosystems). cDNA samples were amplified with Trpv4 (Mm00499025_m1), Pkd2 (Mm00435829_m1), Piezo1 (Mm01241570_g1), Piezo2 (Mm01262433_m1), Cox-2 (Mm00478374_m1), and Gapdh (4352339E) primers and probes (Applied Biosystems) by quantitative realtime RT-PCR using the ABI PRISM 7900 detection system (Applied Biosystems). Samples and standards were run in triplicate and were normalized to the endogenous Gapdh expression. Relative gene levels between samples were determined using the relative standard curve method (ABI Prism 7700 User Bulletin 2; Applied Biosystems).

\section{Statistical analysis}

Results are shown as mean \pm SEM. Unpaired $t$-tests (two-tailed) were used to analyze differences between treated and untreated groups. Comparisons of multiple groups were performed using one-way ANOVA followed by Dunnett's multiple comparison post hoc test or Bonferroni's multiple comparison post hoc test for Cox2 mRNA level comparisons. For all tests, $p<0.05$ was considered significant.

\section{Results}

\section{Arl13b-linker- $\mathrm{Ca}^{2+}$ biosensor detects ciliary $\mathrm{Ca}^{2+}$}

For this study, we developed a novel primary ciliumlocalized, fully ratiometric biosensor using the modified YC3.6 $\mathrm{Ca}^{2+}$-sensitive FRET-based biosensor $(\mathrm{CaB})$ containing ECFP and YPet fused to ARL13B. First, we established that ARL13B localizes to primary cilia in MLO-Y4 osteocyte-like cells and verified ARL13B localization to IMCD primary cilia (Additional file 1: Figure S1A and B) [29]. Our biosensor design consisted of Arl13b at the N terminus followed by a 15-amino-acid-long flexible linker, ECFP, calmodulin, M13 calmodulin-binding region, and YPet at the $C$ terminus (Figure 1A) [20,24]. Addition of $\mathrm{Ca}^{2+}$ leads to increased FRET signal, and transfecting Arl13b-linker-CaB (ALC) enabled us to detect $\mathrm{Ca}^{2+}$ levels within the primary cilium separate from the cytosol. The addition of $5 \mu \mathrm{M}$ ionomycin, a $\mathrm{Ca}^{2+}$ ionophore, in media containing $1.8 \mathrm{mM} \mathrm{Ca}^{2+}$ led to detectable increases in FRET (represented by the emission ratio of YPet:ECFP fluorescence intensity) (Figure 1B, Additional file 2: Video S1). Furthermore, the FRET signal increased at a slower rate and with delay to smaller concentrations of calcium chloride $\left(\mathrm{CaCl}_{2}\right)$ added with ionomycin in $\mathrm{Ca}^{2+}$-free media compared with higher concentrations of $\mathrm{CaCl}_{2}$ (Figure 1C). As expected with a $K_{\mathrm{d}}=250 \mathrm{nM}$, the biosensor activity eventually reaches saturation for all $\mathrm{CaCl}_{2}$ concentrations. Thus, we determined that ALC is sensitive to different levels of ciliary $\mathrm{Ca}^{2+}$.

\section{Mechanical stimulation of MLO-Y4 cells leads to ciliary and cytosolic $\mathrm{Ca}^{2+}$ mobilization}

We preferentially imaged cells with primary cilia having a vertical component prior to flow which typically bent in the direction of flow (Figure 1D). We loaded the $\mathrm{Ca}^{2+}$ indicator dye Fura Red into cells transfected with ALC to monitor cytosolic $\mathrm{Ca}^{2+}$ levels. Use of a Photometrics Quad-View beam splitter allowed us to collect images through several emission filters, and we monitored 


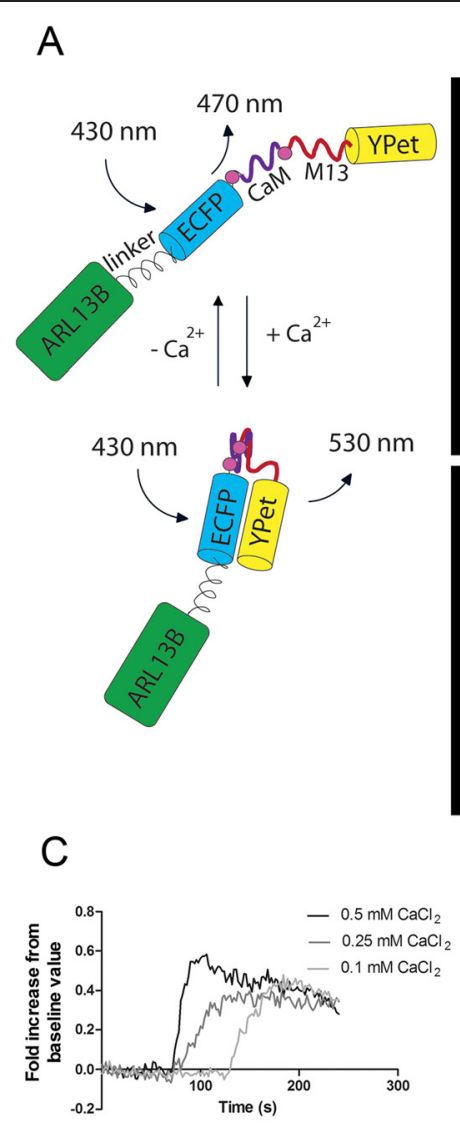

\section{B}
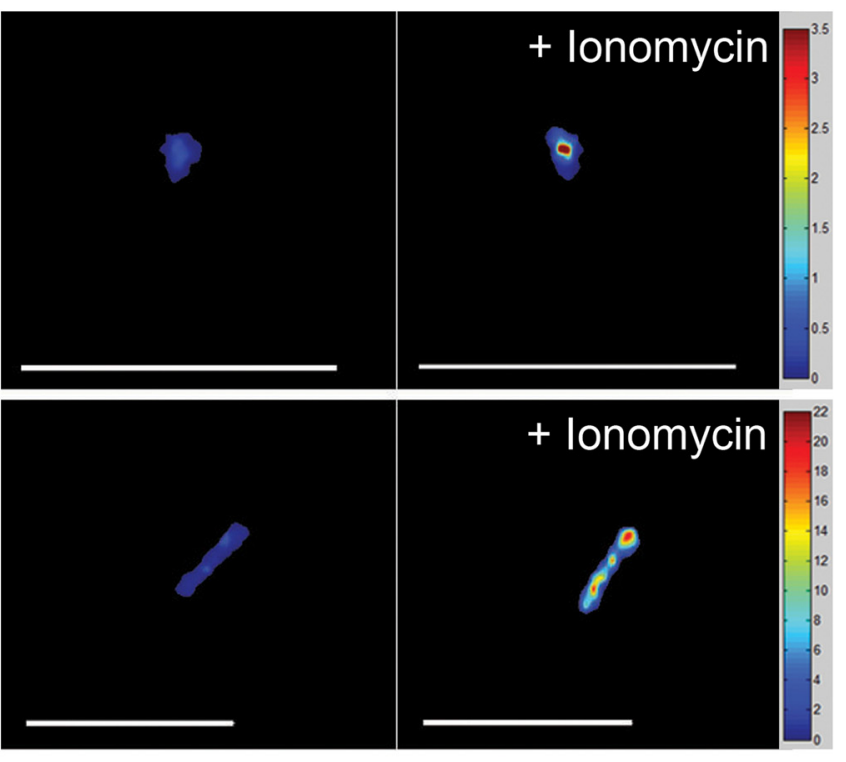

+ lonomycin

D
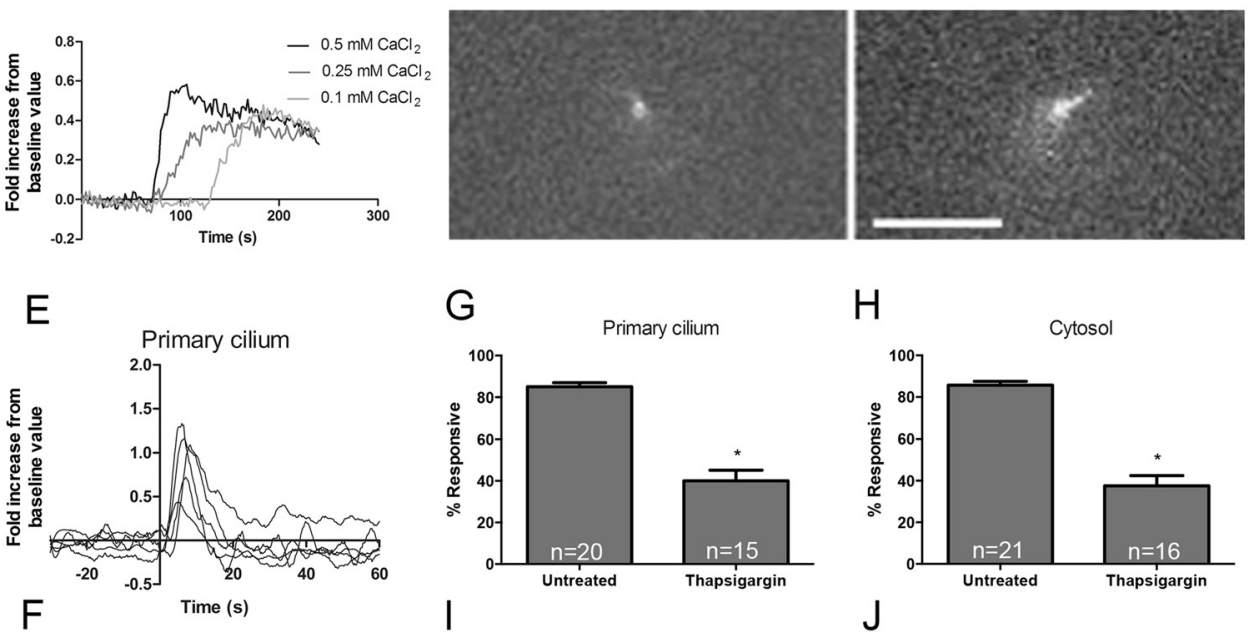

G

$\mathrm{H}$
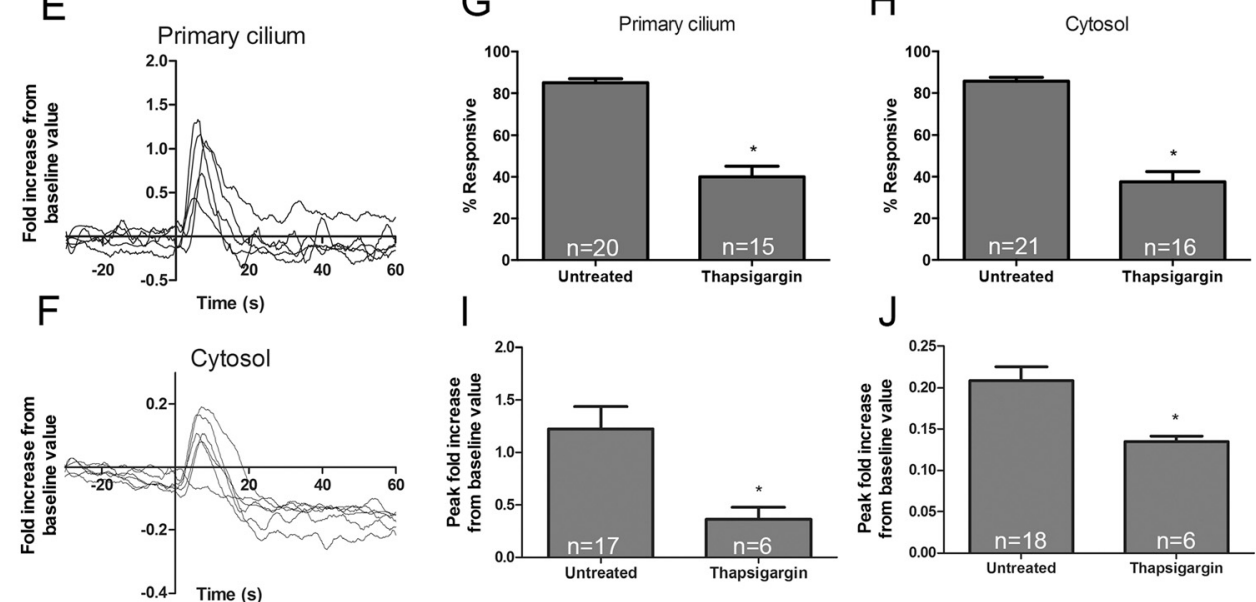

\section{K}
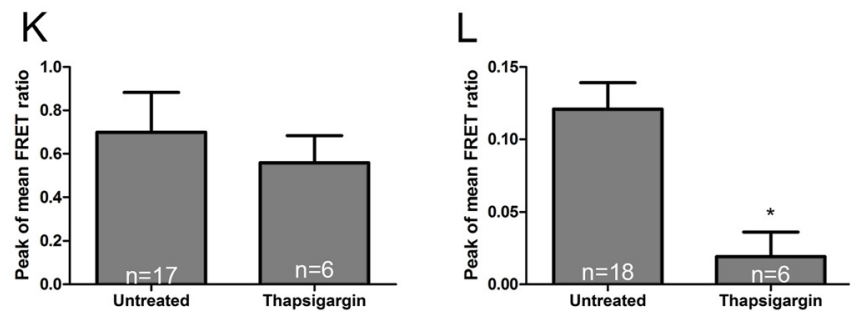

Figure 1 (See legend on next page.) 
(See figure on previous page.)

Figure $1 \mathrm{ALC}$ localizes to the primary cilium and detects changes in ciliary $\mathrm{Ca}^{2+}$ levels. (A) Schematic of primary cilium-localized biosensor, ALC. (B) ALC FRET signal increases when ionomycin is added to media. FRET signal is reported on a pixel-by-pixel basis. Scale bars, $5 \mu \mathrm{m}$. (C) Traces of baseline-normalized FRET signal over time with different $\left[\mathrm{CaCl}_{2}\right]$. (D) YPet fluorescence images of a vertical primary cilium which bent during flow. Scale bars, $10 \mu \mathrm{m}$. (E,F) Individual ciliary and cytosolic $\mathrm{Ca}^{2+}$ measurements during oscillatory fluid flow starting at $t=0 \mathrm{~s}$. $(\mathbf{G}, \mathbf{H})$ Percent of viable MLO-Y4 primary cilia and cytosolic domains exhibiting flow-induced $\mathrm{Ca}^{2+}$ increases $(n=15-21)$. (I,J) Flow-induced Ca ${ }^{2+}$ increases normalized to baseline value in the primary cilium and cytosol with untreated or thapsigargin-treated media (untreated $(n=17$ or 18$)$, thapsigargin $(n=6))$. $(\mathbf{K}, \mathbf{L})$ Average peak response over baseline value for cilia and cytosolic domains with thapsigargin treatment for all viable cells (untreated ( $n=17$ or 18), thapsigargin $(n=6))$. Error bars show \pm SEM $\left({ }^{*} p<0.05\right)$.

ECFP, YPet, and Fura Red signals simultaneously [30]. Application of $1 \mathrm{~Hz}$ OFF resulting in a $10-\mathrm{dyn} / \mathrm{cm}^{2}$ surface shear stress led to ciliary and cytosolic $\mathrm{Ca}^{2+}$ peaks within approximately $8.2 \pm 0.8$ and $8.2 \pm 0.6 \mathrm{~s}$, respectively (Figure $1 \mathrm{E}, n=17$ or 18 ). On an individual cell basis, $57 \%$ of $\mathrm{Ca}^{2+}$ peaks occurred in the primary cilium prior to the cytosol of the same cell. We also stimulated cells transfected with the inactive biosensor mutALC to verify that the observed peaks during $10 \mathrm{dyn} / \mathrm{cm}^{2} \mathrm{OFF}$ were indeed due to increased $\mathrm{Ca}^{2+}$ levels (Additional file 3: Figure S2). Next, cells were treated with thapsigargin, which depletes intracellular $\mathrm{Ca}^{2+}$ stores $(n=6)$. As expected, we found that $\mathrm{Ca}^{2+}$ release from internal stores is a substantial source of flow-induced $\mathrm{Ca}^{2+}$ mobilization in the cytosol. Under thapsigargin treatment, there was a $45 \%$ decrease in responsive samples and a $25 \%$ magnitude reduction averaged from those fewer responsive samples in response to flow (Figure 1G, H). Additionally, under thapsigargin treatment, the peak mean signal from all viable samples in the group was significantly reduced in the cytosol but not in the primary cilium (Figure $1 \mathrm{~K}$, L). We continued to observe flow-induced ciliary $\mathrm{Ca}^{2+}$ peaks, although there were significant decreases in responsiveness and peak magnitude normalized to baseline value (Figure $1 \mathrm{G}-\mathrm{J}$ ). These results imply that $\mathrm{Ca}^{2+}$-permeable channels on the primary cilium also mediate flow-induced $\mathrm{Ca}^{2+}$ entry.

\section{PC2, TRPV4, and PIEZO1 are $\mathrm{Ca}^{2+}$-permeable channels on the primary cilium}

We examined three $\mathrm{Ca}^{2+}$-permeable channels localized to the osteocyte primary cilium: PC2, TRPV4, and PIEZO1. PC2 and TRPV4, among other channels, localize to primary cilia and mediate flow-induced $\mathrm{Ca}^{2+}$ increases in kidney epithelia [15,31]. Coste et al. reported that mechanically activated ion channels PIEZO1 and PIEZO2 are expressed in several murine tissues including kidney and have relatively lower expression in brain and heart tissues [22]. We observed Piezo1 mRNA expression in MLO-Y4 and IMCD cells and Piezo2 $m R N A$ expression only in IMCDs (Additional file 4: Figure S3). We immunostained MLO-Y4 cells for PC2, TPRV4, and PIEZO1 and found that all three channels are present in both the primary cilium and plasma membrane (Figure 2A-C). siRNA transfection reduced protein and mRNA levels compared with scrambled siRNA controls (all groups $(n=4-10)$ vs. control mRNA levels $(n=10), p<0.005)$ ( Figure 2D, E).

\section{TRPV4 mediates flow-induced ciliary $\mathrm{Ca}^{2+}$ increases in osteocytes}

PC2 mediates mechanically induced ciliary and cytosolic $\mathrm{Ca}^{2+}$ signaling in kidney epithelia, and here, our data suggest that osteocyte mechanotransduction is independent of PC2. Following co-transfection of ALC and either Pkd2, Trpv4, or Piezo1 siRNA, MLO-Y4 cells were loaded with Fura Red and exposed to oscillatory flow stimulation $(n=14-16)$. Upon an initial general analysis of primary cilia from all viable cells (ionomycin-responsive), neither thapsigargin nor any of the siRNA-mediated knockdowns of Pkd2, Trpv4, or Piezo1 exhibited a significant difference in flow-induced $\mathrm{Ca}^{2+}$ peak amplitude relative to untreated samples. Similarly, the only significant difference in peak amplitude relative to untreated samples occurred in the cytosol of cells treated with thapsigargin (Additional file 5: Figure S4). Using the spike threshold of $1.5 \times$ baseline, there was no significant difference in the percentage of cells exhibiting a $\mathrm{Ca}^{2+}$ response in the primary cilium and cytosol with Pkd2, Trpv4, and Piezo1 knockdown. To illustrate the role of candidate mechanically activated channels in regulating $\mathrm{Ca}^{2+}$ entry in a different way, we plotted the percent of viable cells exhibiting flow-induced $\mathrm{Ca}^{2+}$ responses as a function of peak amplitude (a multiple of the sample's maximum baseline oscillation amplitude) for all treatment groups. Thus, a flow-induced peak was considered a response if its amplitude was $1.5 \times$ greater than the maximum baseline oscillation amplitude, and we demonstrated that the percentage of cells responding decreased as a peak was considered a larger multiple of maximum baseline oscillation. Out of all the candidate $\mathrm{Ca}^{2}$ ${ }^{+}$-permeable channels, only the loss of Trpv4 clearly impaired the percent of responding cells (Figure 3A). Trpv4 deficiency did not lower the percent of cells exhibiting cytosolic $\mathrm{Ca}^{2+}$ peaks (Figure 3B). Additionally, only thapsigargin treatment affected the percent of cells exhibiting flow-induced cytosolic $\mathrm{Ca}^{2+}$ increases (Figure 3B, $n=6$ ). We analyzed the response of Trpv4 siRNA-treated cells further and found that $75 \%$ of untreated cells had an 

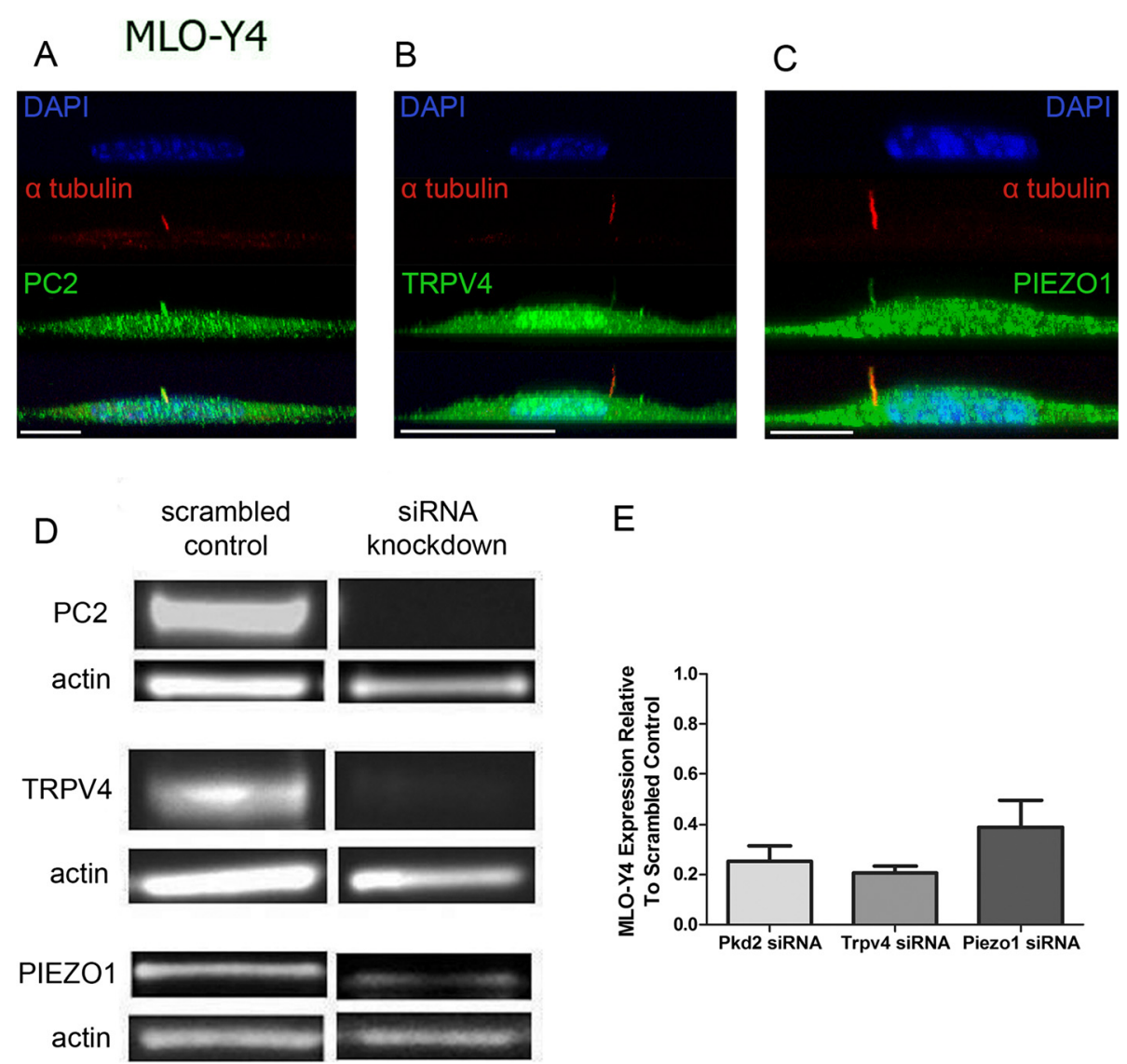

Figure 2 PC2, TRPV4, and PIEZO1 localize to MLO-Y4 primary cilia and plasma membrane. (A-C) Localization of PC2, TRPV4, and PIEZO1 on MLO-Y4 primary cilia and plasma membrane. Acetylated alpha-tubulin is in enriched primary cilia. Scale bars, $10 \mu \mathrm{m}$. (D) Chemiluminescence-detected Western blot of PC2, TRPV4, PIEZO1, and actin protein in MLO-Y4s treated with scrambled control siRNA and Pkd2,Trpv4, or Piezo1 siRNA. (E) Quantified knockdown of Pkd2 $(n=4)$, Trpv4 $(n=10)$, and Piezol $(n=4)$ mRNA expression in MLO-Y4 cells treated with siRNA relative to controls $(n=10)$. Error bars show \pm SEM.

intense response, a $\mathrm{Ca}^{2+}$ peak height at least five times the maximum baseline oscillation amplitude, compared with only $30 \%$ of Trpv4 siRNA-treated cells that had intense ciliary $\mathrm{Ca}^{2+}$ peaks. $P k d 2$ and Piezo1 deficiencies did not inhibit the percent of ciliary or cytosolic $\mathrm{Ca}^{2+}$ peaks. Interestingly, Piezo1 knockdown sensitized the cytosolic $\mathrm{Ca}^{2+}$ response to flow, perhaps because of a different $\mathrm{Ca}^{2+}$ permeable channel.

As mentioned earlier, there is a delay in peak FRET signal with lower $\mathrm{Ca}^{2+}$ concentrations relative to higher $\mathrm{Ca}^{2+}$ concentrations. Compared with untreated samples, ciliary and cystolic $\mathrm{Ca}^{2+}$ peaks were delayed in MLO-Y4 cells treated with thapsigargin or deficient in Trpv4 and Piezo1 (Figure 3C, D). These differences were not statistically significant in cells lacking Piezo1. On an individual cell basis, there was no significant change in the percent of peaks occurring in the primary cilium prior to the cytosol. $57 \pm 5 \%$ of peaks first occurred in the primary cilium in untreated cells, compared with $75 \pm 13 \%$ in thapsigargin-treated cells, compared with $54 \pm 5 \%$ in Pkd2 siRNA-treated cells, $43 \pm 5 \%$ in Trpv4 siRNA- treated cells, and $55 \pm 6 \%$ in Piezo1 siRNA-treated cells. Thus, in cells deficient in Trpv4, there was a decrease in the percent of $\mathrm{Ca}^{2+}$ peaks occurring first in the primary cilium in cells deficient in $\operatorname{Tr} p v 4$, although this difference was not significant. Collectively, these results suggest that fluid flow mechanically activates TRPV4 channels on the primary cilium. Separately, fluid flow also activates intracellular $\mathrm{Ca}^{2+}$ release, which diffuses from the cytosol into the primary cilium microdomain.

\section{TRPV4 is required for osteocyte mechanotransduction}

Next, we were interested in determining if TRPV4 also mediates osteocyte mechanotransduction at the transcriptional level in addition to regulating early ciliary $\mathrm{Ca}^{2+}$ mobilization. The Cox-2 gene encodes an enzyme which catalyzes formation of $\mathrm{PGE}_{2}$, an osteogenic cytokine released by osteoblasts and osteocytes in response to mechanical stimulation, and Cox-2 expression increases correspond to more $\mathrm{PGE}_{2}$ release [14]. After 5 min of OFF stimulation (identical to the imaging experiments) and a rest period of $55 \mathrm{~min}$, we isolated and 


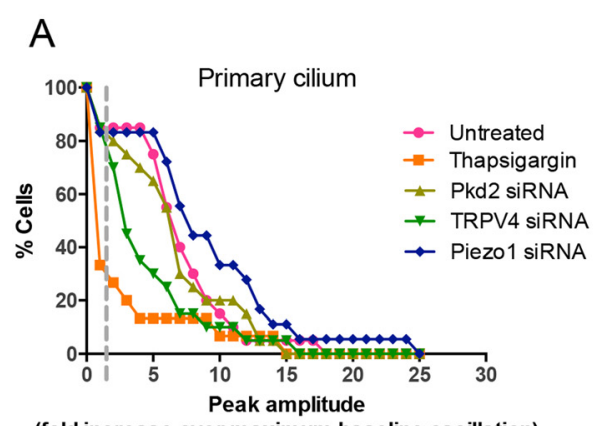

(fold increase over maximum baseline oscillation)
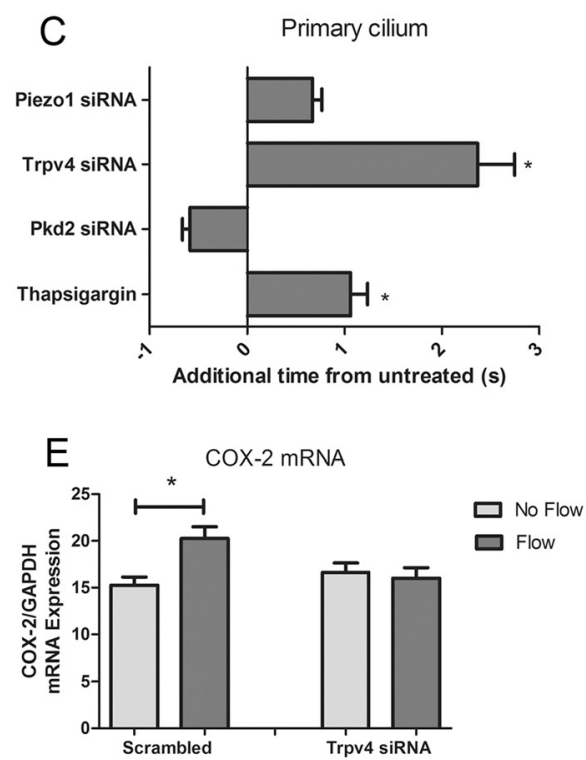

B

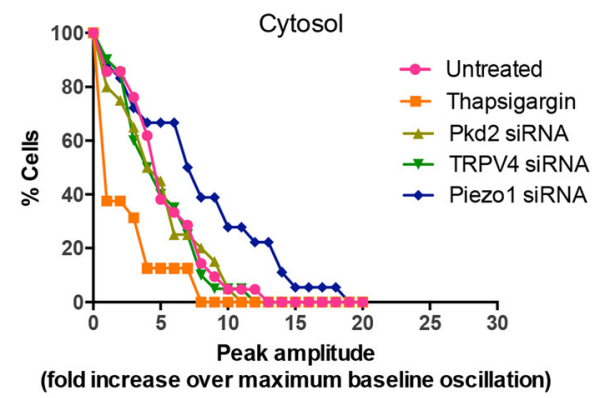

D Cytosol
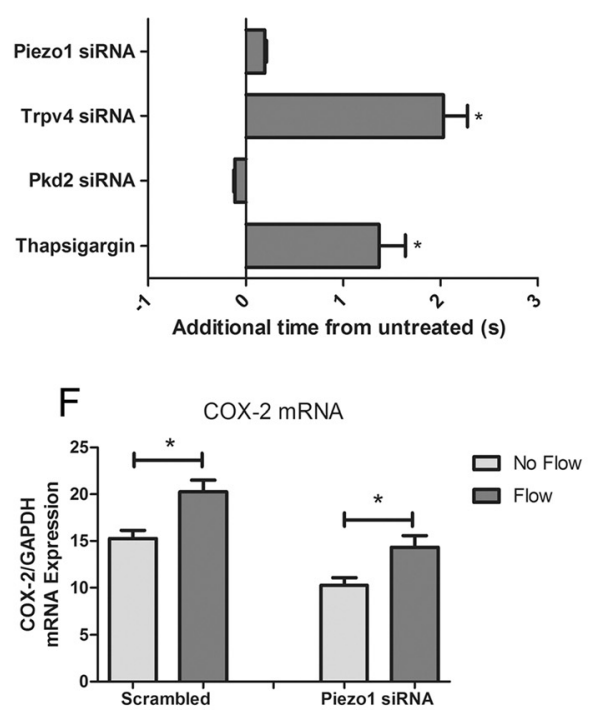

Figure 3 TRPV4 plays a role in osteocyte mechanotransduction. $(\mathbf{A}, \mathbf{B})$ Percent of viable cells exhibiting flow-induced $\mathrm{Ca}^{2+}$ response as a function of peak amplitude (a multiple of the sample's maximum baseline oscillation amplitude) $(n=15-21)$. (C,D) Timing of ciliary and cytosolic Ca ${ }^{2+}$ peaks of treated cells relative to untreated controls (untreated $(n=15)$, thapsigargin $(n=5$ or 6$)$ ), Pkd2, Trpv4, and Piezo $1(n=14-16)$. (E,F) Levels of normalized Cox-2 mRNA expression in scrambled siRNA and Trpv4 or Piezo 1 siRNA-treated cells with and without 5 min of oscillatory flow exposure $(n=9-11)$. Error bars show \pm SEM $\left({ }^{*} p<0.05\right)$.

quantified Cox-2 mRNA expression relative to the endogenous control Gapdh $(n=9-11)$. Scrambled siRNAtransfected cells demonstrated a flow-induced increase in Cox-2 mRNA expression levels, and this flow-induced response was blocked in cells lacking Trpv4 (1.3 \pm 0.3 -fold (control) vs. $1.0 \pm 0.1$-fold (Trpv4) increase) (Figure 3E). MLO-Y4 cells transfected with scrambled control siRNA and Trpv4 siRNA expressed similar levels of Cox-2 mRNA expression at baseline. Interestingly, Piezo1 deficiency did not affect downstream flow-induced changes in Cox-2 mRNA. MLO-Y4 cells transfected with Piezo1 siRNA demonstrated a $1.4 \pm 0.2$-fold flow-induced increase in Cox-2 mRNA expression which was not significantly different from controls, although they exhibited lower baseline Cox-2 mRNA expression levels (Figure 3F). We did not examine the role of PC2 in flow-induced transcriptional changes due to the absence of ciliary and cytosolic $\mathrm{Ca}^{2+}$ peak amplitude or timing changes with $P k d 2$ deficiency. Taken together, these data suggest that loss of Trpv4 alters osteocyte mechanotransduction at the molecular and transcriptional levels.

\section{Primary cilium-regulated mechanisms of mechanotrans-} duction are different in kidney epithelia and osteocytes With the suggestion that the osteocyte primary ciliummediated mechanism of mechanotransduction depends on TRPV4 and not PC2, we conducted similar flow studies with kidney epithelial cells to verify that this difference was due to cell type and not the experimental approach. We immunostained IMCD cells for PC2 and found similar localization relative to MLO-Y4 cells (Figure 4A). As expected and previously reported, $P k d 2$ knockdown (11.85 $\pm 0.03 \%$ relative to IMCD control mRNA levels, $p<0.005$ (Figure 4B, C, $n=4)$ ) blocked steady flow-induced ciliary and cytosolic $\mathrm{Ca}^{2+}$ increases in IMCDs normalized to 
baseline value, and these differences were statistically significant (Figure 4D-G) [18].

\section{Discussion}

In this study, we directed a FRET-based $\mathrm{Ca}^{2+}$ biosensor to the primary cilium and loaded cells with a nontargeted fluorescent $\mathrm{Ca}^{2+}$ indicator dye to resolve the local $\mathrm{Ca}^{2+}$ environment in the osteocyte primary cilium from the cytosol. We monitored ciliary and cytosolic $\mathrm{Ca}^{2+}$ levels using an epifluorescence microscopy system and observed flowinduced $\mathrm{Ca}^{2+}$ peaks in both domains. Trpv4 deficiency reduced flow-induced ciliary $\mathrm{Ca}^{2+}$ peaks but did not impair flow-induced cytosolic $\mathrm{Ca}^{2+}$ mobilization, illustrating that the primary cilium microdomain is distinct from the cytosol. Thapsigargin treatment impaired flow-induced ciliary and cytosolic $\mathrm{Ca}^{2+}$ peaks, demonstrating that intracellular $\mathrm{Ca}^{2+}$ release and separate $\mathrm{Ca}^{2+}$ entry through TRPV4 are both components of ciliary $\mathrm{Ca}^{2+}$ mobilization. In contrast, knockdown of $P k d 2$ and Piezo1 did not affect ciliary or cytosolic $\mathrm{Ca}^{2+}$ peaks. Last, we linked the role of TRPV4 in regulating flow-induced ciliary $\mathrm{Ca}^{2+}$ mobilization with a downstream osteogenic response at the transcriptional level by determining that flow-induced changes in Cox-2 expression depend on TRPV4. Collectively, our study demonstrates that the loading-induced ciliary $\mathrm{Ca}^{2+}$ mechanism is different between kidney epithelia and osteocytes.
After observing flow-induced $\mathrm{Ca}^{2+}$ peaks in both the osteocyte primary cilium and cytosol, we were motivated to identify the source of the ciliary $\mathrm{Ca}^{2+}$ peak. To deplete intracellular $\mathrm{Ca}^{2+}$ stores, we treated cells with thapsigargin and continued to observe ciliary $\mathrm{Ca}^{2+}$ peaks, suggesting that $\mathrm{Ca}^{2+}$-permeable channels on the primary cilium have a role in mediating flow-induced $\mathrm{Ca}^{2+}$ entry. However, thapsigargin treatment did lower flow-induced ciliary and cytosolic $\mathrm{Ca}^{2+}$ peak magnitudes and responsiveness compared with untreated cells, indicating that intracellular $\mathrm{Ca}^{2+}$ release is a component of flow-induced ciliary $\mathrm{Ca}^{2+}$ mobilization in osteocytes. Furthermore, a statistically significant delay in ciliary and cytosolic $\mathrm{Ca}^{2+}$ peaks occurred in thapsigargintreated cells compared with controls. Thus, our data demonstrate that intracellular $\mathrm{Ca}^{2+}$ release contributes, in part, to the local primary cilia $\mathrm{Ca}^{2+}$ environment and suggests that the primary cilium serves as an important signal integrator.

It is important to note that a general ensemble analysis of our data did not reveal an effect of PC2, TRPV4, or PIEZO1 on flow-induced ciliary $\mathrm{Ca}^{2+}$ mobilization. In fact, the only significant reduction in peak $\mathrm{Ca}^{2+}$ mobilization was demonstrated in the cytosol with thapsigargin treatment. On the one hand, although the effect of thapsigargin on flow-induced $\mathrm{Ca}^{2+}$ mobilization was clear, using such a potent agent provides limited details. As expected, extracting the finer details of the role of $\mathrm{Ca}^{2}$
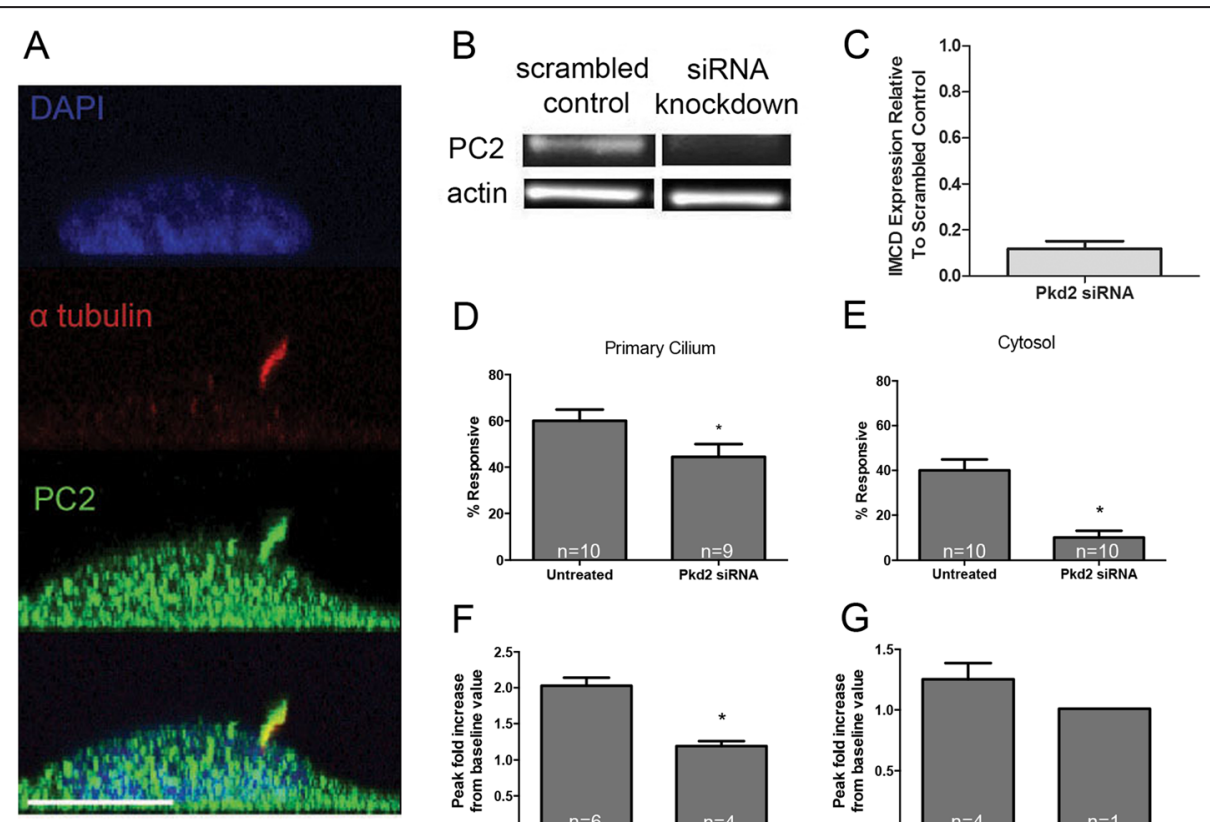

$\mathrm{E}$
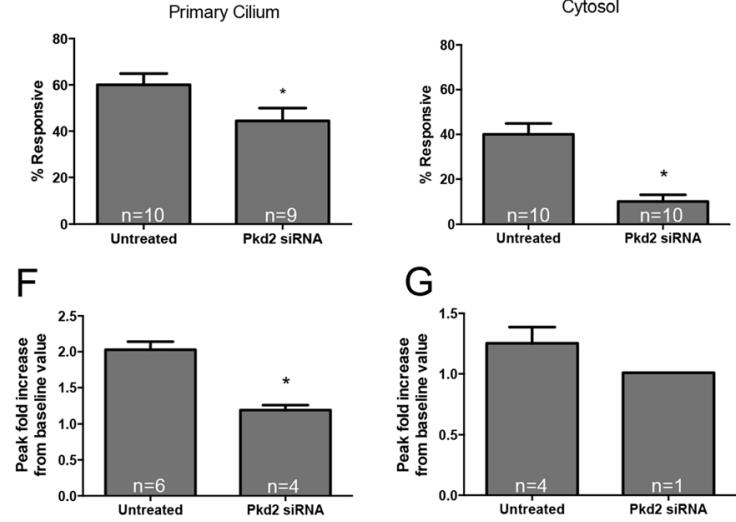

G

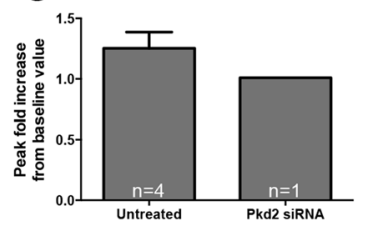

Figure 4 PC2 mediates kidney epithelial mechanotransduction. (A) PC2 localizes to IMCD primary cilia and plasma membrane. Scale bar, 10 um. (B) Chemiluminescence-detected Western blot of PC2 and actin protein in IMCDs treated with scrambled control siRNA and Pkd2 siRNA. (C) Quantified knockdown of Pkd2 mRNA expression in IMCD cells treated with siRNA relative to controls $(n=4)$. (D,E) Percent of viable IMCD primary cilia and cytosolic domains exhibiting flow-induced $\mathrm{Ca}^{2+}$ increases $(n=9-10)$. Error bars show \pm SEM $\left({ }^{*} p<0.05\right)$. (F,G) Flow-induced Ca ${ }^{2+}$ increases normalized to baseline value in the primary cilium and cytosolic domains of responsive cells with $P$ kd2 siRNA-mediated knockdown (primary cilium: untreated $(n=6), P k d 2(n=4)$; cytosol: untreated $(n=4), P k d 2(n=1))$. 
channels in targeted $\mathrm{Ca}^{2}$ channel blocking experiments required more selective analysis, which included categorizing cells into responders and nonresponders. While selecting a discriminating threshold can be confounding to the analysis, we found no significant difference in average peak ciliary $\mathrm{Ca}^{2+}$ mobilization with any treatment, suggesting that the results of this approach are not sensitive to the magnitude of the threshold (Additional file 5: Figure S4).

In this study, we present evidence that fluid flow activates TRPV4 on the primary cilium membrane and mediates $\mathrm{Ca}^{2+}$ influx. Using immunocytochemistry techniques, we determined that the stretch-activated $\mathrm{Ca}^{2+}$-permeable channel TRPV4 localizes to the primary cilium and plasma membrane. Interestingly, TRPV4 (and PC2 and PIEZO1) appears throughout the cell, which is consistent with TRPV4 and PC2 immunostaining in the literature [32-35]. While the distribution of the channels appear higher on the cell membrane relative to the primary cilium and may mediate a larger $\mathrm{Ca}^{2+}$ flux compared with the flux into the primary cilium, it is likely that the machinery and spatiotemporal molecular pathways unique to the primary cilium play a role in downstream mechanotransduction. Our flow experiments revealed that Trpv4 knockdown lowered flow-induced ciliary $\mathrm{Ca}^{2+}$ peaks but did not impair cytosolic $\mathrm{Ca}^{2+}$ peaks. Unlike kidney epithelia, where $\mathrm{Ca}^{2+}$ reportedly enters the primary cilium through PC2 and induces CICR via ryanodine receptor activation [18], Trpv4 deficiency in osteocytes did not affect cytosolic $\mathrm{Ca}^{2+}$ mobilization. This result suggests that the TRPV4mediated ciliary $\mathrm{Ca}^{2+}$ microdomain does not regulate CICR in osteocytes. This is different from astrocytes, where TRPV4-mediated CICR regulates neurovascular coupling in an $\mathrm{IP}_{3} \mathrm{R}$-regulated system [36]. It is also possible that other mechanically activated $\mathrm{Ca}^{2+}$-permeable channels compensate for the loss of TRPV4 function in the cytosol, which is consistent with data from this study showing that the loss of Piezo1 may sensitize cells to flow. Knockdown of PC2, TRPV4, and PIEZO1 channels did not impair the flow-induced cytosolic $\mathrm{Ca}^{2+}$ response, which suggests that a different mechanism is in play that maintains normal cytosolic $\mathrm{Ca}^{2+}$ levels. Taken together, TRPV4's location in an area of high membrane strain on the primary cilium and dependence of the flow-induced ciliary $\mathrm{Ca}^{2+}$ peak on TRPV4 suggest that the primary cilium acts as a $\mathrm{Ca}^{2+}$ and mechanical signaling nexus dependent on TRPV4.

Consistent with these results, previously, Malone et al. blocked flow-induced extracellular $\mathrm{Ca}^{2+}$ entry into MC3T3 osteoblasts using gadolinium chloride, which did not eliminate the flow-induced cytosolic $\mathrm{Ca}^{2+}$ flux [14]. In addition to demonstrating that flow-induced cytosolic $\mathrm{Ca}^{2+}$ flux is not dependent on extracellular $\mathrm{Ca}^{2}$ ${ }^{+}$entry through stretch-activated channels, Malone et al. also reported that the removal of primary cilia did not affect flow-induced cytosolic $\mathrm{Ca}^{2+}$ flux in osteocytes. The results in this study, here, are consistent with the previous paper and provide additional insight to the understanding of osteocyte mechanotransduction. Using advanced imaging techniques that provide enhanced resolution, our data demonstrate that flow-induced cytosolic $\mathrm{Ca}^{2+}$ flux is independent of extracellular $\mathrm{Ca}^{2+}$ entry through stretch-activated channels; furthermore, flowinduced ciliary $\mathrm{Ca}^{2+}$ flux is dependent on the $\mathrm{Ca}^{2+}$-permeable, stretch-activated TRPV4 channel. Thus, our data suggest that $\mathrm{Ca}^{2+}$ mobilization occurs differently in the cytosol versus the primary cilium during osteocyte mechanotransduction.

Our understanding of primary cilium bending mechanics and mechanical forces on the plasma membrane covering the primary cilium is essential to elucidating the molecular mechanism of mechanotransduction mediated by the primary cilium. Recently, Young et al. studied the tension force distribution along a primary cilium under flow and suggested that stretch-activated ion channels are likely to be activated and open near the base of the primary cilium where tension force is the highest [37]. While primary cilia bending is one potential physical event, it is possible that primary cilium deflection is not physiologic and that mechanical loading of the primary cilium occurs in other ways. For example, $\beta$ 1 integrins are localized to MDCK primary cilia, and $\beta-1$ integrins have been implicated in mediating osteocyte mechanotransduction and loading-induced bone formation [38-40]. Thus, increased membrane tension is not limited to primary cilia bending and may involve primary cilia integrin-extracellular matrix interactions.

We anticipate that TRPV4 will be an attractive pharmacologic target for treating disuse-induced bone loss due to its role mediating osteocyte mechanotransduction and its sensitivity to existing biochemical agents (agonists: , GSK1016790A, and RN1747 and antagonist: RN1734) [4143]. Thus, treatment with TRPV4 agonists and therapies that elongate osteocyte primary cilia (lithium chloride, hydrogen sulfide, interleukin-1) to enhance mechanical strain levels may amplify osteogenic responses and prevent disuse-induced bone loss in patients restricted to bed rest $[8,44,45]$. Furthermore, O'Conor et al. have shown that TRPV4 plays a role as a physical transducer in chondrocytes, which may provide insight into functional cartilage tissue engineering approaches [46].

Other groups have suggested that TRPV4 is a candidate therapeutic target for bone loss disease. Mizoguchi et al. and Masuyama et al. have examined TRPV4 deficiency in unloading-induced bone formation, and they determined that Trpv4 knockout reduces unloadinginduced bone loss due to suppressed osteoclast numbers and impaired bone resorption [47,48]. Interestingly, 
Mizoguchi et al. do not exclude the possibility that Trpv4 is expressed by osteocytes. Osteocytes are mechanosensing cells in bone that regulate osteoclasts' resorption activities, and it will be important to understand the role of TRPV4 in the population of cells involved in mechanotransduction. The effect of an osteocyte-specific Trpv4 deletion in loading-induced bone formation in vivo would provide evidence indicating whether TRPV4 is involved in the mechanotransduction process versus restricted to mediating osteoclast numbers and bone resorption. Additionally, it is important to recognize that primary cilia play important roles in development; however, in this study, we have not examined how TRPV4 plays a role in developmental ciliary pathways such as Hedgehog and Wnt signaling pathways.

While Jin et al. reported that flow-induced $\mathrm{Ca}^{2+}$ mobilization occurs in primary cilia before cytosolic $\mathrm{Ca}^{2+}$ increases in kidney epithelial cells, our flow studies do not demonstrate a clear difference in the timing between ciliary and cytosolic $\mathrm{Ca}^{2+}$ peaks in osteocytes [18]. While the amount of ciliary $\mathrm{Ca}^{2+}$ peaks occurring before cytosolic $\mathrm{Ca}^{2+}$ peaks is numerically higher than the number of ciliary $\mathrm{Ca}^{2+}$ peaks occurring after cytosolic $\mathrm{Ca}^{2+}$ peaks, it is unclear if ciliary $\mathrm{Ca}^{2+}$ triggers cytosolic $\mathrm{Ca}^{2+}$ increases. Unlike the side-dimension imaging method leveraged by Jin et al. to capture calcium signaling along the length of the primary cilium, our imaging method collected signal from only a part of the primary cilium that was in plane. Thus, we are unable to characterize a relationship between ciliary and cytosolic $\mathrm{Ca}^{2+}$ peak timing.

Several other groups have demonstrated that flowinduced ciliary $\mathrm{Ca}^{2+}$ mobilization is dependent on PC2 in kidney epithelia [15,18,31]. Our data suggest that flow-induced ciliary $\mathrm{Ca}^{2+}$ mobilization is dependent on TRPV4, and not PC2, in osteocytes. We conducted similar flow studies with kidney epithelial cells to verify that this difference was due to cell type and not the experimental approach. Our studies with IMCD cells also showed that flow-induced ciliary and cytosolic $\mathrm{Ca}^{2+}$ increases depend on PC2. The consistency in our results suggests that the mechanism of mechanotransduction mediated by primary cilia varies across different tissue contexts. Another difference between the MLO-Y4 and IMCD flow studies was the type of flow regime, consisting of OFF resulting in a 10 -dyn $/ \mathrm{cm}^{2}$ shear stress for MLO-Y4 cells and steady flow resulting in a 5-dyn $/ \mathrm{cm}^{2}$ shear stress for IMCD cells. Previously, Malone et al. determined that flow-induced $\mathrm{Ca}^{2+}$ flux differences in MC3T3-E1 osteoblasts and MDCK kidney cells did not depend on these specific flow regimes, which suggests that primary cilium-mediated mechanosensation in osteoblasts and kidney cells is indeed different [14]. Thus, the application of different but physiologically relevant mechanical loads was appropriate for elucidating intricacies in the mechanotransduction mechanism in IMCD and MLO-Y4 cells.

Interestingly, in addition to being well-established in kidney epithelial mechanotransduction [15,18,31], PC2 has recently been implicated in osteocyte mechanotransduction [49]. The authors found siRNA-mediated knockdown of PC2 inhibited downstream flow-induced nitric oxide production and inducible nitric oxide synthase. While fluid flow-induced shear stress is known to activate the nitric oxide pathway, this activation occurs over a much longer time scale of hours compared to $\mathrm{Ca}^{2+}$ flux of seconds and minutes. Here, we studied the early signaling response to flow occurring within seconds after exposure to flow. Thus, our finding that PC2 was independent of mechanically induced ciliary and cytosolic $\mathrm{Ca}^{2+}$ signaling in osteocytes does not contradict the findings by $\mathrm{Xu}$ et al. It is possible that PC2 is involved in the later downstream signaling response to flow. While we found that $\mathrm{PC} 2$ may not be involved in the early $\mathrm{Ca}^{2+}$ response to flow, it is nonetheless an important channel in bone. $P k d 2$ mutations have been implicated in skeletal development [50,51], and mutations in $P k d 1$, encoding the other subunit of the polycystin complex, have impaired both skeletal development and adaptation [52].

\section{Conclusions}

In conclusion, this study highlights the specialization of primary cilium mechanisms across different tissue contexts. Here, we demonstrate that mechanically stimulated ciliary $\mathrm{Ca}^{2+}$ mobilization is different between kidney epithelia and osteocytes. Strikingly, the osteocyte primary cilium forms a distinct microdomain from the cytosol during mechanical loading. The primary cilium microdomain may help maintain spatiotemporal organization within the cell which allows numerous molecular mechanisms to occur with just a limited number of signaling molecules. We expect that the $\mathrm{Ca}^{2}$ ${ }^{+}$-permeable channel TRPV4 will be an attractive therapeutic target for bone loss disease because of its location in an area of high membrane strain on the primary cilium, demonstrated role as a physical transducer in osteocytes in this study and chondrocytes in a recent study by O'Conor et al., and sensitivity to existing biochemical agents [46]. Furthermore, we anticipate that other flow studies on second messenger-mediated pathways in the primary cilium microdomain and loadinginduced bone formation studies using mice with an osteocyte-targeted deletion of Trpv4 will elucidate how TRPV4-mediated $\mathrm{Ca}^{2+}$ entry in the primary cilium microdomain regulates osteogenic responses to mechanical loads. 


\section{Additional files}

Additional file 1: Figure S1. ARL13B localizes to primary cilia in MLOY4 and IMCD cells. (A-B) IMCD and MLO-Y4 cells fixed and stained for acetylated alpha tubulin and ARL13B, demonstrating localization of ARL13B to the primary cilium.

Additional file 2: Video S1. Ciliary $\mathrm{Ca}^{2+}$ increases detected by ALC. Images of an individual primary cilium in a time-lapse video. MLO-Y4 cells were transfected with ALC, cultured in $1.8 \mathrm{mM} \mathrm{Ca}^{2+}$-containing media, and treated with ionomycin which permeabilizes the plasma membrane to $\mathrm{Ca}^{2+}$. Images were captured at 10-s intervals. Display rate is three frames per second.

Additional file 3: Figure S2. Mutant $\mathrm{CaB}$ and $\mathrm{ALC}$ do not exhibit flow-induced $\mathrm{Ca}^{2+}$ peaks. Deletions of $\mathrm{Trp}^{3}$ and $\mathrm{Phe}^{17}$ in the $\mathrm{M} 13$ region inhibit FRET changes during $\mathrm{Ca}^{2+}$ increases. (A-B) In initial testing and prior to targeting the mutated biosensor to the primary cilium, MutCaB failed to detect flow-induced $\mathrm{Ca}^{2+}$ increase with the addition of $10 \mu \mathrm{M}$ $\mathrm{CaCl}_{2}(n=3)$ and steady flow $\left(5 \mathrm{dyn} / \mathrm{cm}^{2}\right)(n=2)$. (C) MutALC failed to detect flow-induced $\mathrm{Ca}^{2+}$ increases occurring with oscillatory fluid flow $\left(10 \mathrm{dyn} / \mathrm{cm}^{2}\right)(n=4)$.

Additional file 4: Figure S3. MLO-Y4 cells express Piezo1 and not Piezo2. (A) Piezo1 and (B) Piezo2 mRNA levels in MLO-Y4 cells, IMCD cells, and adult murine (C57BL/6) brain and heart relative to GAPDH mRNA expression $(n=4-5)$. Piezo $1=1.6 \pm 0.2$ and Piezo2 $=0.003 \pm 0.001$ in MLOY4 cells. Error bars show \pm SEM.

Additional file 5: Figure S4. FRET ratios of all viable MLO-Y4 cells eXposed to fluid flow. (A) Mean FRET ratios over time, where solid lines indicate the mean background-corrected FRET ratios (no threshold applied) while the dashed lines indicate SEM. (B) Flow-induced $\mathrm{Ca}^{2+}$ peak amplitude averaged from all viable cells (no threshold applied). Error bars show \pm SEM.

\section{Abbreviations}

Cox-2: Cyclooxygenase 2; IMCD: Inner medullary collecting duct; PC2: Polycystin-2; TRPV4: Transient receptor potential vanilloid 4; CaB: Calcium biosensor; ALC: Arl13b-linker-calcium biosensor.

\section{Competing interests}

The authors declare that they have no competing interests.

\section{Authors' contributions}

$K L L$ and $C R J$ conceived the study, designed the experiments, and wrote the paper. YW contributed molecular tools. KLL and MCC built the ALC plasmid. KLL performed Western blotting and GRT-PCR. MDG carried out immunostaining and imaging. KLL, MCC, and MDG performed the imaging experiments and analyzed data. KLL, AMN, and CRJ contributed to interpretation of the data. All authors reviewed and critically revised the paper and approved the final manuscript.

\section{Acknowledgements}

We thank Drs. Kenji Kontani and Kristen Verhey for the Arl13b plasmid and discussions. We would also like to thank Dr. Mingxing Ouyang for providing guidance on using the $\mathrm{CaB}$ and for his critical review of the manuscript. We acknowledge Drs. X. Edward Guo and Andrew Baik for the use of their epifluorescence imaging system. Additionally, we thank Dr. Kevin Dooley for technical discussions and appreciate assistance from Divya Pathack, Paul Muir, and Aishwarya Raja with experimental protocols. This work was supported by National Institute of Arthritis and Musculoskeletal and Skin Diseases/National Institute of Health (NIAMS/NIH) grant AR062177 (to CR Jacobs), NIAMS/NIH grant AR059038 (to AM Nguyen), and National Science Foundation (NSF) grant GRFP 0707425 (to KL Lee). Funding sources did not play a role in the design, collection, analysis, interpretation of data, writing of the manuscript, or decision to submit for publication.

\section{Author details}

'Department of Biomedical Engineering, Columbia University, 351 Engineering Terrace, MC 8904, 1210 Amsterdam Ave, New York, NY 10027, USA. ${ }^{2}$ Jacobs Technion-Cornell Innovation Institute, Cornell Tech, New York, NY 10011, USA. ${ }^{3}$ Department of Biotechnology, University of British
Columbia, Vancouver, BC V6T 1Z4, Canada. ${ }^{4}$ Bioengineering Department, UC San Diego, La Jolla, CA 92093, USA.

Received: 14 August 2014 Accepted: 28 April 2015

Published online: 29 May 2015

\section{References}

1. Wang SQ, Wei C, Zhao G, Brochet DX, Shen J, Song LS et al. (2004) Imaging microdomain Ca2+ in muscle cells. Circ Res 94:1011-1022

2. Nelson MT, Cheng H, Rubart M, Santana LF, Bonev AD, Knot HJ et al. (1995) Relaxation of arterial smooth muscle by calcium sparks. Science 270:633-637

3. Ajubi NE, Klein-Nulend J, Alblas MJ, Burger EH, Nijweide PJ (1999) Signal transduction pathways involved in fluid flow-induced PGE2 production by cultured osteocytes. Am J Physiol 276:E171-E178

4. You J, Reilly GC, Zhen X, Yellowley CE, Chen Q, Donahue HJ et al. (2001) Osteopontin gene regulation by oscillatory fluid flow via intracellular calcium mobilization and activation of mitogen-activated protein kinase in MC3T3-E1 osteoblasts. J Biol Chem 276:13365-13371

5. Jones TJ, Nauli SM (2012) Mechanosensory calcium signaling. Adv Exp Med Biol 740:1001-1015

6. Wheatley DN, Wang AM, Strugnell GE (1996) Expression of primary cilia in mammalian cells. Cell Biol Int 20:73-81

7. Rohatgi R, Milenkovic L, Scott MP (2007) Patched1 regulates hedgehog signaling at the primary cilium. Science 317:372-376

8. Wann AK, Zuo N, Haycraft CJ, Jensen CG, Poole CA, McGlashan SR et al. (2012) Primary cilia mediate mechanotransduction through control of ATPinduced Ca2+ signaling in compressed chondrocytes. FASEB J 26:1663-1671

9. Muhammad H, Rais Y, Miosge N, Ornan EM (2012) The primary cilium as a dual sensor of mechanochemical signals in chondrocytes. Cell Mol Life Sci 69:2101-2107

10. Temiyasathit $S$, Tang WJ, Leucht $P$, Anderson CT, Monica SD, Castillo AB et al. (2012) Mechanosensing by the primary cilium: deletion of Kif3A reduces bone formation due to loading. PLoS One 7, e33368

11. Egorova AD, Khedoe PP, Goumans MJ, Yoder BK, Nauli SM, ten Dijke P et al. (2011) Lack of primary cilia primes shear-induced endothelial-to-mesenchymal transition. Circ Res 108:1093-1101

12. Praetorius HA, Spring KR (2002) Removal of the MDCK cell primary cilium abolishes flow sensing. J Membrane Biol 191:69-76

13. Praetorius HA, Spring KR (2001) Bending the MDCK cell primary cilium increases intracellular calcium. J Membr Biol 184:71-79

14. Malone AM, Anderson $C T$, Tummala P, Kwon RY, Johnston TR, Stearns $T$ et al. (2007) Primary cilia mediate mechanosensing in bone cells by a calcium-independent mechanism. Proc Natl Acad Sci U S A 104:13325-13330

15. Nauli SM, Alenghat FJ, Luo Y, Williams E, Vassilev P, Li X et al. (2003) Polycystins 1 and 2 mediate mechanosensation in the primary cilium of kidney cells. Nat Genet 33:129-137

16. Delling M, DeCaen PG, Doerner JF, Febvay S, Clapham DE (2013) Primary cilia are specialized calcium signalling organelles. Nature 504:311-314

17. Su S, Phua SC, Derose R, Chiba S, Narita K, Kalugin PN et al. (2013) Genetically encoded calcium indicator illuminates calcium dynamics in primary cilia. Nat Methods 10:1105-1107

18. Jin X, Mohieldin AM, Muntean BS, Green JA, Shah JV, et al. (2013) Cilioplasm is a cellular compartment for calcium signaling in response to mechanical and chemical stimuli. Cell Mol Life Sci. 71:2165-78

19. Fill M, Copello JA (2002) Ryanodine receptor calcium release channels. Physiol Rev 82:893-922

20. Ouyang M, Sun J, Chien S, Wang Y (2008) Determination of hierarchical relationship of Src and Rac at subcellular locations with FRET biosensors. Proc Natl Acad Sci U S A 105:14353-14358

21. Whitaker M (2010) Genetically encoded probes for measurement of intracellular calcium. Methods Cell Biol 99:153-182

22. Coste B, Mathur J, Schmidt M, Earley TJ, Ranade S, Petrus MJ et al. (2010) Piezo1 and Piezo2 are essential components of distinct mechanically activated cation channels. Science 330:55-60

23. Prasad RM, Jin X, Nauli SM (2014) Sensing a sensor: identifying the mechanosensory function of primary cilia. Biosensors 4:16

24. Wang Y, Botvinick EL, Zhao Y, Berns MW, Usami S, Tsien RY et al. (2005) Visualizing the mechanical activation of Src. Nature 434:1040-1045 
25. Ikura M, Clore GM, Gronenborn AM, Zhu G, Klee CB, Bax A et al. (1992) Solution structure of a calmodulin-target peptide complex by multidimensional NMR. Science 256:632-638

26. Palmer AE, Tsien RY (2006) Measuring calcium signaling using genetically targetable fluorescent indicators. Nat Protoc 1:1057-1065

27. Hung CT, Pollack SR, Reilly TM, Brighton CT (1995) Real-time calcium response of cultured bone cells to fluid flow. Clin Orthop Relat Res 313:256-269.

28. Jing D, Baik AD, Lu XL, Zhou B, Lai X, Wang L et al. (2014) In situ intracellular calcium oscillations in osteocytes in intact mouse long bones under dynamic mechanical loading. FASEB J 28:1582-1592

29. Sharma N, Kosan ZA, Stallworth JE, Berbari NF, Yoder BK (2011) Soluble levels of cytosolic tubulin regulate ciliary length control. Mol Biol Cell 22:806-816

30. Baik AD, Qiu J, Hillman EM, Dong C, Guo XE (2013) Simultaneous tracking of $3 \mathrm{D}$ actin and microtubule strains in individual MLO-Y4 osteocytes under oscillatory flow. Biochem Biophys Res Commun 431:718-723

31. Kottgen M, Buchholz B, Garcia-Gonzalez MA, Kotsis F, Fu X, Doerken M et al. (2008) TRPP2 and TRPV4 form a polymodal sensory channel complex. J Cell Biol 182:437-447

32. Cai Y, Maeda Y, Cedzich A, Torres VE, Wu G, Hayashi T et al. (1999) Identification and characterization of polycystin-2, the PKD2 gene product. J Biol Chem 274:28557-28565

33. Geng L, Okuhara D, Yu Z, Tian X, Cai Y, Shibazaki S et al. (2006) Polycystin-2 traffics to cilia independently of polycystin-1 by using an N-terminal RVxP motif. J Cell Sci 119:1383-1395

34. Mendoza SA, Fang J, Gutterman DD, Wilcox DA, Bubolz AH, Li R et al. (2010) TRPV4-mediated endothelial Ca2+ influx and vasodilation in response to shear stress. Am J Physiol Heart Circ Physiol 298:H466-H476

35. Chen WH, Tzen JT, Hsieh CL, Chen YH, Lin TJ, Chen SY et al. (2012) Attenuation of TRPV1 and TRPV4 expression and function in mouse inflammatory pain models using electroacupuncture. Evid Based Complement Alternat Med 2012:636848

36. Dunn KM, Hill-Eubanks DC, Liedtke WB, Nelson MT (2013) TRPV4 channels stimulate Ca2+-induced Ca2+ release in astrocytic endfeet and amplify neurovascular coupling responses. Proc Natl Acad Sci U S A 110:6157-6162

37. Young YN, Downs M, Jacobs CR (2012) Dynamics of the primary cilium in shear flow. Biophys J 103:629-639

38. Praetorius HA, Praetorius J, Nielsen S, Frokiaer J, Spring KR (2004) Beta1-integrins in the primary cilium of MDCK cells potentiate fibronectin-induced Ca2+ signaling. Am J Physiol Renal Physiol 287:F969-F978

39. Litzenberger JB, Kim JB, Tummala P, Jacobs CR (2010) Beta1 integrins mediate mechanosensitive signaling pathways in osteocytes. Calcif Tissue Int 86:325-332

40. Litzenberger JB, Tang WJ, Castillo AB, Jacobs CR (2009) Deletion of beta 1 integrins from cortical osteocytes reduces load-induced bone formation. Cell Mol Bioeng 2:416-424

41. Watanabe H, Vriens J, Prenen J, Droogmans G, Voets T, Nilius B et al. (2003) Anandamide and arachidonic acid use epoxyeicosatrienoic acids to activate TRPV4 channels. Nature 424:434-438

42. Thorneloe KS, Sulpizio AC, Lin Z, Figueroa DJ, Clouse AK, McCafferty GP et al. (2008) N-((1S)-1-\{[4-((2S)-2-\{[(2,4-dichlorophenyl)sulfonyl]amino\}-3-hydroxypropanoyl)-1 -piperazinyl]carbonyl\}-3-methylbutyl)-1-benzothiophene-2-carboxamide (GSK1016790A), a novel and potent transient receptor potential vanilloid 4 channel agonist induces urinary bladder contraction and hyperactivity: part I. J Pharmacol Exp Ther 326:432-442

43. Vincent F, Acevedo A, Nguyen MT, Dourado M, DeFalco J, Gustafson A et al. (2009) Identification and characterization of novel TRPV4 modulators. Biochem Biophys Res Commun 389:490-494

44. Miyoshi K, Kasahara K, Miyazaki I, Asanuma M (2011) Factors that influence primary cilium length. Acta Med Okayama 65:279-285

45. Han SJ, Kim Jl, Park KM (2014) P26 hydrogen sulfide elongates primary cilia in the kidney tubular epithelial cells. Nitric Oxide 39:S24.

46. O'Conor CJ, Leddy HA, Benefield HC, Liedtke WB, Guilak F (2014) TRPV4mediated mechanotransduction regulates the metabolic response of chondrocytes to dynamic loading. Proc Natl Acad Sci U S A 111:1316-1321

47. Mizoguchi F, Mizuno A, Hayata T, Nakashima K, Heller S, Ushida T et al. (2008) Transient receptor potential vanilloid 4 deficiency suppresses unloadinginduced bone loss. J Cell Physiol 216:47-53

48. Masuyama R, Vriens J, Voets T, Karashima Y, Owsianik G, Vennekens R et al. (2008) TRPV4-mediated calcium influx regulates terminal differentiation of osteoclasts. Cell Metab 8:257-265
49. Xu H, Guan Y, Wu J, Zhang J, Duan J, An L et al. (2014) Polycystin 2 is involved in the nitric oxide production in responding to oscillating fluid shear in MLO-Y4 cells. J Biomech 47:387-391

50. Turco AE, Padovani EM, Chiaffoni GP, Peissel B, Rossetti S, Marcolongo A et al. (1993) Molecular genetic diagnosis of autosomal dominant polycystic kidney disease in a newborn with bilateral cystic kidneys detected prenatally and multiple skeletal malformations. J Med Genet 30:419-422

51. Khonsari RH, Ohazama A, Raouf R, Kawasaki M, Kawasaki K, Porntaveetus $T$ et al. (2013) Multiple postnatal craniofacial anomalies are characterized by conditional loss of polycystic kidney disease 2 (Pkd2). Hum Mol Genet 22:1873-1885

52. Xiao Z, Dallas M, Qiu N, Nicolella D, Cao L, Johnson M et al. (2011) Conditional deletion of Pkd1 in osteocytes disrupts skeletal mechanosensing in mice. FASEB J 25:2418-2432

\section{Submit your next manuscript to BioMed Central and take full advantage of:}

- Convenient online submission

- Thorough peer review

- No space constraints or color figure charges

- Immediate publication on acceptance

- Inclusion in PubMed, CAS, Scopus and Google Scholar

- Research which is freely available for redistribution 